\title{
Reply to: Emphysematous pyelonephritis: a case report
}

\author{
Vitorino Modesto dos Santos ${ }^{1,2}$ \\ ${ }^{1}$ Internal Medicine Department, Armed Forces Hospital, Brasília-DF; ${ }^{2}$ Catholic University Medical Course, Brasília-DF, Brazil
}

\section{Letter to Editor}

To the Editor:

I read the article of Tiraterra et al. (doi: 10.4081/ itjm.2015.553) about emphysematous pyelonephritis affecting a 68 -year-old woman with hypertension and type 2 diabetes mellitus. ${ }^{1}$ She had anemia, neutrophilic leukocytosis and elevated levels of inflammatory markers; the urine culture showed Escherichia coli, and imaging studies revealed gas in the left kidney parenchyma. Worthy of note, the radiological condition of the patient was class 2 by Huang and Tseng classification, which often requires clinical management plus percutaneous catheter drainage. ${ }^{1}$ In spite of uncontrolled diabetes, hydronephrosis, proteinuria and renal function impairment, the result of her early medical treatment and use of effective antimicrobials was successful. The patient was discharged, in good clinical conditions, after three weeks of hospitalization. ${ }^{1}$ The authors emphasized the role of rapid diagnosis and prompt adequate antibiotic therapy, which have changed traditional options for management of emphysematous pyelonephritis. ${ }^{1,2}$

Actually, the case study herein commented is an

Correspondence: Vitorino Modesto dos Santos, Armed Forces Hospital, Estrada do Contorno do Bosque s/n, Cruzeiro Novo, 70658-900, Brasília-DF, Brazil.

Tel.: +55.61.39662103 - Fax: +55.61.32331599.

E-mail: vitorinomodesto@gmail.com

Key words: Emphysematous pyelonephritis; elderly; treatment.

Conflict of interest: the author declares no potential conflict of interest.

Received for publication: 26 July 2015.

Accepted for publication: 6 August 2015.

This work is licensed under a Creative Commons Attribution NonCommercial 4.0 License (CC BY-NC 4.0).

(C) Copyright V. Modesto dos Santos, 2016

Licensee PAGEPress, Italy

Italian Journal of Medicine 2016; 10:77

doi:10.4081/itjm.2015.628 important contribution in this setting; however, I would like to highlight the result of the Italian study with a similar Brazilian case. ${ }^{2}$ A 70 -year-old woman with hypertension and type 2 diabetes mellitus had the diagnoses of bilateral nephrolithiasis, cystitis, pielitis and pyelonephritis emphysematous by E. coli. Similarly to the commented report, the radiological classification was consistent with class 2 , and early diagnosis plus immediate antibiotic therapy controlled her infection in two weeks. ${ }^{2}$ In both patients, the agent was E. coli, which has been detected in up to $75 \%$ of these cases. ${ }^{2}$ The Italian as well as the Brazilian authors prescribed levofloxacin and meropenem, ${ }^{1}$ and ciprofloxacin, ${ }^{2}$ empirical options that were concordant with respective susceptibility tests. ${ }^{2}$

Early diagnosis and immediate antibiotic therapy may control this potentially severe condition without using invasive procedure, ${ }^{1,2}$ but the routine management of emphysematous pyelonephritis would merit well-controlled evaluations. Although with the inherent limitations of single case studies, these reports may enhance the knowledge about this uncommon entity.

\section{References}

1. Tiratterra F, Feigusch L, Villani C, et al. Emphysematous pyelonephritis: a case report. Ital $\mathrm{J}$ Med 2015;9:370-2.

2. Santos VM, Cançado ACV, Gebrim DG, et al. Cistitis, pielitis y pielonefritis enfisematosas em diabética con nefrolitíasis. Pren Med Argent 2013;99:688-91. 